\title{
Identifying vowels in CVC syllables: Effects of inserting silence and noise
}

\author{
ELLEN M. PARKER and RANDY L. DIEHL \\ University of Texas, Austin, Texas
}

\begin{abstract}
Listeners were asked to identify natural vowels in $/ \mathbf{d}$ _d/ context under various deletion conditions. Deletion intervals, which were centered about the syllable midpoint, ranged from $60 \%$ to $90 \%$ of the syllable duration and contained either silence or broadband noise. In one condition, the three syllable types were $/ \mathrm{did} /, / \mathrm{ded} /$, and $/ \mathrm{dud} /$; in the other condition, the three syllable types were $/ \mathrm{dId} /, / \mathrm{d} \varepsilon \mathrm{d} /$, and $/ \mathrm{d} \Lambda \mathrm{d} /$. Identification performance in the $60 \%$ and $70 \%$ deletion conditions was not substantially worse than for full syllables. Even the $90 \%$ deletion conditions yielded performance well above chance, indicating that significant coarticulatory information for vowels is contained in the first and last 10 or $15 \mathrm{msec}$ of the syllable. For the short-vowel stimuli (/dId/, $/ \mathrm{ded} /$, and $/ \mathrm{d} \wedge \mathrm{d} /$ / in the $90 \%$ deletion condition, a series of discriminant analyses were performed to assess the relative contribution of several acoustic variables to the statistical separation of the vowel categories. Several different combinations of acoustic variables (including formant frequencies at particular temporal locations and formant frequency differences over time) were sufficient to yield significant separation of the three vowel categories. However, in general, the performance of the discriminant classification program correlated only weakly with the identification performance of the listeners.
\end{abstract}

For the purposes of linguistic description, speech is almost always represented as sequences of discrete, temporally nonoverlapping segments (e.g., phonemes or phones) or feature bundles. Although this discrete representation is more or less consistent with listeners' subjective experience, it is well known to be fundamentally at odds with underlying phonatory and articulatory dynamics and with actual acoustic outputs. Speech segments tend to be coarticulated, that is, produced in a temporally overlapping manner, such that articulatory (and hence acoustic) trajectories from segment to segment are shortened and smoothed. As emphasized by investigators at Haskins Laboratories (Liberman, Cooper, Shankweiler, \& Studdert-Kennedy, 1967) and elsewhere, there is no way to partition the speech signal in time so as to isolate acoustically each of the individual phonemes.

According to one traditional view, coarticulation can be described as an assimilation of contextual properties to a segment. Lindblom (1963), for example, proposed an assimilatory account of vowel "undershoot" effects in consonantal environments. (Formant trajectories for consonant-vowel-consonant syllables often fail to attain the "target" frequencies characteristic of sustained vowels produced in isolation.) He suggested that the undershoot observed with lower stress levels and faster articulatory rates is owing to the earlier arrival of the postvocalic con-

This work was supported by National Institutes of Health Grant NS 16412. We wish to thank Ellen Gorthey for assisting with the acoustic analysis of the stimuli and Keith Kluender for his critical comments on an earlier version of the manuscript. Requests for reprints should be sent to Randy L. Diehl, Department of Psychology, 330 Mezes, University of Texas, Austin, Texas 78712 . trol signal which deflects the articulator away from its target trajectory and toward the consonantal configuration. Implicit in the assimilatory account is the claim that there is significant spatial as well as temporal overlap in the production of adjacent segments. That is, coarticulation occurs to the extent that adjacent segments are produced by the same articulators.

An alternative perspective, promoted by Fowler (1980, 1983) and based on earlier empirical and theoretical work by Kozhevnikov and Chistovich (1965), Ohman (1966, 1967), and Perkell (1969), assumes that consonants and vowels are coproduced rather than articulatorily assimilated. Coproduction implies temporally overlapping articulations by neuromuscular systems that are, to a large degree, functionally and anatomically separate. Although vowels involve relatively slow and continuous changes in the overall vocal-tract shape, consonants are produced as abrupt local occlusions of the vocal tract. Both Ohman $(1966,1967)$ and Perkell (1969) proposed that, to a first approximation, vowel production is controlled by extrinsic tongue muscles responsible for positioning the tongue body, whereas consonantal occlusion is effected by intrinsic tongue muscles that regulate tongue shape. By this view, consonantal articulations are simply superimposed on a continuous underlying vowel trajectory.

Our purpose here is not to evaluate the relative merits of these two accounts of coarticulation, but instead to consider their possible implications for the perception of vowels in consonantal environments. Both accounts clearly suggest that vowel information, that is, acoustic structure specific to or correlated with vowel category, is present throughout a consonant-vowel-consonant (CVC) syllable, at least from the moment of release to the mo- 
ment of final closure. The assimilatory account suggests this by virtue of the assumed spatiotemporal overlap between the consonant and vowel gestures. Initial formant transitions, for example, are assumed to be structured by an interaction of consonant and vowel and should, therefore, carry information about both segments. The coproduction account, although denying spatial overlap, makes virtually the same prediction. If consonants and vowels are produced in a temporally overlapping manner by separate neuromuscular systems, the formant transitions will reflect the orthogonal contributions of both systems.

The available perceptual data confirm that $\mathrm{CV}$ and VC formant transitions contain sufficient information to specify vowel identity at levels above chance. In a study by Strange, Jenkins, and Johnson (1983), listeners were asked to identify the vowel in naturally produced $/ \mathrm{bVb} /$ syllables that had been modified in various ways. One type of modification involved deleting (i.e., zeroing the amplitude of) the middle $50 \%$ to $65 \%$ of each syllable, an interval assumed to include any steady-state portion of the vowel. Despite the loss of this information, listeners made relatively few vowel identification errors, even in the multiple-talker condition ( $14 \%$ vs. $5 \%$ for unaltered syllables). Thus, overall syllable duration, together with information carried by the formant transitions, was sufficient to cue vowel identity in most instances. Other deletion studies have generally produced similar findings (Blumstein \& Stevens, 1980; Jenkins, Strange, \& Edman, 1983; Kuehn \& Moll, 1972; Ohde \& Sharf, 1977; Tekieli \& Cullinan, 1979; Winitz, Scheib, \& Reeds, 1972).

Our aim in the present study was to explore further the perceptual consequences of coarticulation in CVC syllables and, in particular, to determine the nature and extent of vowel information present in the vicinity of the initial and final closure intervals. Accordingly, we planned to assess the minimal CV and VC transition segment durations capable of supporting above-chance levels of vowel identification accuracy and to measure, in a preliminary way, the relative informational value of selected aspects of the acoustic signal.

\section{Methodological Preliminaries}

Following Strange et al. (1983), we used a test stimulus set consisting of unmodified CVC syllables as well as syllables whose central portions had been deleted. There were several significant ways, however, in which our experimental approach differed from that of Strange et al. First, because our concern was with minimal transition cues for vowel identity, we used a greater range of deletion intervals (60\% to $90 \%$ of overall syllable duration vs $50 \%$ to $65 \%$ in the study by Strange et al.).

Second, the stimulus set used by Strange et al. included vowel categories of varying intrinsic durations. Such durational differences have been shown to provide cues to vowel identity (Ainsworth, 1972; Mermelstein, 1975; Verbrugge \& Isenberg, 1978). Inasmuch as our focus was on minimal spectral cues, we used vowel sets whose mem- ber categories did not differ significantly in intrinsic duration. Our aim was to neutralize the role of durational information in the vowel identification task. ${ }^{1}$

Third, whereas Strange et al. replaced the deleted portion of each syllable with silence, we inserted either silence or broadband noise within the deletion intervals. The noise condition was motivated by the following considerations. Insertion of silence within a CVC may not only remove vowel information but may also create spurious information for consonantal occlusion (i.e., a glottal or oral stop). Because oral stops in particular would be expected to have substantial coarticulatory effects on adjacent vowels, any increase in identification error rate might be due as much to the unintended presence of the perceived "stop" as to the reduced vowel information.

The use of broadband noise instead of silence in the deletion intervals may mitigate this problem. With appropriately chosen intensity values for the noise and the remaining stimulus, it is unlikely that the noise would be perceived as an intrinsic part of the stimulus, especially if the noise spectrum had low-frequency components uncharacteristic of, say, $/ \mathrm{s} /$ or $/ \mathrm{f} /$. Thus, noise insertion might well allow removal of information without simultaneously creating unwanted new information. Before proceeding, we will try to justify this last claim.

A number of investigators (Elfner, 1971; Houtgast, 1974; Thurlow, 1957; Thurlow \& Elfner, 1959; Warren, Obusek, \& Ackroff, 1972) have reported that when two auditory stimuli of differing intensities are alternated without intervening silence, the fainter stimulus is often perceived as being continuously present whereas the louder one sounds intermittent. Following Warren et al. (1972), we refer to this effect as auditory induction. Roughly speaking, induction occurs when the louder stimulus has the required intensity and spectral characteristics to mask the fainter stimulus if the two are presented simultaneously (Houtgast, 1974; Warren et al.; 1972). Induction effects have been shown (using broadband noise as the more intense stimulus) with steady tones, tones rising or falling in frequency, steady vowel-like sounds, and even music (Plomp demonstration recording). What is especially important from our perspective is that the louder stimulus is usually perceived as being separate from the "continuous" fainter stimulus. Thus, broadband noise interruption of a speech signal will presumably remove information without creating new, and perhaps erroneous, information about the phonetic identity of that signal.

Although induction effects may be enhanced by repetitive alternation of stimuli, experiments conducted by Warren and his colleagues (e.g., Warren \& Obusek, 1971) suggest that such repetition is not a necessary condition for their occurrence. These investigators have shown that when a speech sound in a longer utterance is replaced by broadband noise, listeners usually report hearing the deleted sound and cannot accurately locate the noise relative to the utterance. This "phonemic restoration" appears to be merely a special case of auditory induction. 
Pols and Schouten (1978) reported a study in which portions of initial voiceless stops were deleted and replaced either by silence or noise. Despite its potential masking effect, noise insertion produced considerably fewer consonant identification errors than did silence insertion. Pols and Schouten attributed this result to the interfering effect of the "click sensation" that occurred at stimulus onset in the silence-insertion condition. However, it is not obvious why a click (a transient broadband stimulus) should produce more interference than noise (a temporally extended broadband stimulus). Our own interpretation is that, although the noise undoubtedly removed some consonantal information, the silence had the additional effect of producing misinformation about place value. Unlike the noise, the silence would have effectively redefined the end of the apparent consonantal closure interval and hence the beginning of the CV transitions. These transitions would thus be shorter in duration and have different onset frequencies, both of which effects normally accompany certain changes in place value. Whatever the correct interpretation of these findings, the critical fact is that noise insertion had a far less deleterious effect on consonant identification than silence insertion. A similar pattern of results might, therefore, be expected in the case of vowel deletion.

Our strategy of removing internal portions of the syllable and leaving both endpoints intact is a departure from most of the deletion studies listed earlier, which used CV or VC syllables and removed signal segments from the vowel end. A potentially serious problem with the latter approach is that, in addition to removing vowel and/or consonant information, the deletion process can also create misinformation about vowel identity. As mentioned earlier, syllable duration is an effective vowel cue. Artificially shortening a syllable is therefore likely to provide inappropriate durational cues that lead to vowel misidentification. For example, in the study by Tekieli and Cullinan (1979), the intrinsically long vowels $/ \mathrm{i} /, / \mathrm{u} /$, and $/ æ /$ tended to be identified, following deletion, as the short vowels $/ I /, / v /$, and $/ \varepsilon /$, respectively. It is, of course, problematic whether such identifications should be counted as errors.

\section{METHOD}

\section{Stimuli}

The stimuli were derived from a set of $/ \mathrm{dVd} /$ syllables produced by two male and two female talkers who were natives or long-term residents of Texas and who ranged in age from the early to the late $20 \mathrm{~s}$. There were two sets of syllables: one containing the short lax vowels $/ I /, \mid \varepsilon /$, and $/ \Lambda /$ (pronounced "did," "dead," and "dud," respectively), and the other containing the long tense vowels $/ \mathrm{i}$, /e/, and /u/ (pronounced "deed," "dade," and "dude," respectively). The three vowel categories within each set were selected on the basis of having very similar intrinsic durations (House, 1961; Peterson \& Lehiste, 1960). (See Methodological Preliminaries.)

The syllables were recorded in a soundproof room (Industrial Acoustics Corporation) with a Teac $2300 S$ tape recorder and a Shure Unidyne 5545 microphone. The talkers were instructed to read writ- ten representations of the six syllable types from notecards and were coached by the experimenter to maintain a moderate range of loudness and utterance rate. Approximately 30 tokens of each syllable type were produced by a given talker. Of these, four tokens were selected for use in the actual experiment. The principal selection criteria were: (1) good phonetic quality as judged by the experimenters, and (2) an average syllable duration that varied negligibly across the three vowel categories of each vowel-length condition. Syllable duration, defined here as the interval between the end of the initial consonant closure and the beginning of the final consonant closure, was measured with a Spectraphonics real-time spectrograph display.

The 96 syllable tokens ( 4 talkers $\times 6$ vowels $\times 4$ tokens) were rerecorded with gain adjustments to reduce the range of intensity variation to about $1 \mathrm{~dB}$ within a vowel-length condition. The items were then low-pass filtered with a cutoff of $4.9 \mathrm{kHz}$ and digitized at a $10-\mathrm{kHz}$ sampling rate on a DEC PDP-11/34A computer in the Speech Perception Laboratory at the University of Texas at Austin.

A waveform display and editing program was used to produce modified versions of each syllable. Before performing the main deletion operations, we removed any final release bursts from the syllables. For each $/ \mathrm{dVd} /$ token, there were four deletion interval conditions ranging from $60 \%$ to $90 \%$ of overall syllable duration, as measured from intial burst to final closure onset. The deletion intervals were determined automatically, without regard to waveform zero-crossings. They were centered at the temporal midpoint of each syllable and contained either silence or broadband noise at an intensity level 2-5 dB greater than the peak value of the original syllable. This relatively high noise level was used to enhance the likelihood of auditory induction (see above).

Two audio tapes were prepared, one containing the short-vowel stimuli and the other the long-vowel stimuli. The undeleted version of each syllable (with the final release burst removed) and the eight modified versions were included for a total of 432 stimuli (4 talkers $\times 3$ vowels $\times 4$ tokens $\times 9$ stimulus modification conditions) per tape. Following D/A conversion and low-pass filtering (4.9-kHz cutoff frequency), the stimulus items were recorded in a random order with an interstimulus interval of $5 \mathrm{sec}$.

\section{Subjects and Procedure}

Six male and six female graduate psychology students at the University of Texas at Austin served as subjects. All were native speakers of American English, and most had lived in Texas for at least 3 years.

The stimuli were presented in a sound-attenuated room via a Teac A2300S tape recorder, Dynaco ST80 amplifier, and TDH-39 earphones at a comfortable listening level ( $80 \mathrm{~dB}$ SPL for the noise segments). The subjects were told that they would hear tokens of $/ \mathrm{dVd} /$ words, most of which would be interrupted by silent or noisy intervals. A small sample of test items representing all the deletion conditions was first presented to familiarize the subjects with the various types of stimulus modification. For the actual test, the subjects were instructed to identify the short-vowel items by circling the words "did," "dead," or "dud" on an answer sheet. Similarly, the long-vowel stimuli were to be identified by circling "deed," "dade," or "dude." The long-vowel session was held 8 weeks after the short-vowel session. All 16 subjects served in both sessions.

\section{RESULTS AND DISCUSSION}

The error rates for the various deletion conditions are displayed in Figure 1. Not shown here are the error rates for the unmodified syllables, which were $5.0 \%$ for the short vowels and $3.1 \%$ for the long vowels. An analysis of variance for the modified stimulus conditions indicated 
significant main effects of deletion interval $[F(3,270)=$ $95.55, \mathrm{p}<.001]$, vowel length $[\mathrm{F}(1,90)=13.83$, $\mathrm{p}<.001]$, and type of insertion $[\mathrm{F}(1,90)=11.62$, $\mathrm{p}<.001]$. In addition, there was a significant interaction between the factors of deletion interval and insertion type $[F(3,270)=15.70, p<.001]$. Tukey post hoc analyses revealed that noise insertion produced significantly more identification errors than silence insertion $(\mathrm{p}<.001)$, but only at the $90 \%$ deletion interval. At $60 \%$ deletion, there was a slight, nonsignificant, reversal of this effect. Thus, our hypothesis that noise would be less deleterious than silence was not sustained.

We had speculated that the insertion of silence might not only remove vowel information, but also create spurious information for consonantal occlusion. If the silent gap were perceived as an oral stop, such as $/ \mathrm{p} /$ or $/ \mathrm{t} /$, then the listener would presumably be expecting coarticulatory effects on vowel formant trajectories, and misidentifications would result. In fact, however, both phonetically trained experimenters agreed that the inserted silence created a percept much more like a glottal than an oral stop. Because a glottal stop has virtually no coarticulatory influence on adjacent vowels, one would not expect the kind of perceptual interference that, say, an oral stop would produce.

It appears that at $90 \%$ deletion, the noise produced substantial forward and backward masking effects on the remaining vowel stimulus. This would account for the much lower error rates for silence insertion at that interval. On the other hand, masking seems to have had little effect at the shorter deletion intervals.

In our earlier discussion of auditory induction, we suggested that the insertion of relatively intense, broadband noise would allow us to delete vowel information without creating misinformation about vowel identity. A comparison of our results with those of Jenkins et al. (1983) provides clear support for this view. Along with a "silentcenter" condition similar to that used by Strange et al. (1983), Jenkins et al. included a "hiss-center" condition in which the intermediate silent interval of each syllable was replaced by a naturally produced $/ \mathrm{J} /$ noise at an intensity considerably lower than the portion of the speech signal that was deleted. Unlike our noise-insertion condition, this hiss-center condition would not be expected to yield auditory induction. (Recall that induction occurs only if the noise has the necessary intensity and spectral characteristics to mask the vowel portion of the stimulus, when presented simultaneously. The / $/$ / noise used by Jenkins et al. satisfies neither the intensity nor the spectral requirements.) Rather, the $/ \int /$ noise was most likely heard as a constituent phoneme, the presence of which might cause inappropriate perceptual adjustments for assumed coarticulatory effects. Although in our experiment the effects of noise insertion and silence insertion did not differ reliably over a deletion-interval range of $60 \%$ to $80 \%$, Jenkins et al. obtained significantly more errors in the hiss-center condition than in the silence-insertion con- dition $(18.7 \%$ vs. $7.6 \%$ ) for deletion intervals in the $50 \%$ $65 \%$ range.

Jenkins et al. (1983) offered two possible explanations for their results:

Perhaps the sudden transition into another speech-like sound in midsyllable was interfering rather than facilitating in perceiving the continuity of the syllable. Alternatively, the level of noise relative to vocalic signal may have been sufficient to mask relevant information in the initial and final segments (p. 445).

In view of our results for comparable deletion intervals, we can safely rule out the masking interpretation. Our inserted noise was far more likely than theirs to mask the adjacent vowel, but it produced nominally fewer errors at the $60 \%$ deletion interval than did silence. The "continuity" explanation offered by Jenkins et al. is probably closer to the mark, but we would offer a slight modification: the perceived $/ \mathrm{J} /$ no doubt created expectations of a coarticulatory effect on the vowel formant trajectories, and, in compensating for this assumed coarticulatory effect, the listeners tended to misjudge the vowel category.

In any case, the clear difference between our results and those of Jenkins et al. supports our claims about auditory induction. For moderate deletion intervals, insertion of relatively intense, broadband noise appears to remove vowel information without creating spurious information for other, unintended phonetic segments. Especially in those instances in which silence is likely to produce misinformation (e.g., in the study by Pols \& Schouten, 1978, reviewed earlier), noise insertion may be the most appropriate strategy in deletion experiments.

We turn now to other aspects of our data. The more accurate performance on long vowels was completely predictable. At each deletion interval, there was obviously a greater absolute duration of the remaining syllable for the long-vowel condition. Also, the long-vowel stimuli were spectrally more distinctive than the short vowels.

Figure 1 shows that error rate is a positively accelerated function of deletion interval. It seems likely, however, that the underlying relation is more nearly linear. What perhaps obscures this linearity is, first, the substantial masking effects of the noise at the $90 \%$ deletion interval and, second, the presence of floor effects in the error data, especially for the long-vowel condition. If we exclude the $90 \%$ noise-insertion condition, and if we average the silence- and noise-insertion results for the other interval conditions, we see a roughly linear trend for the short vowels, where floor effects are less pronounced. The significance of this linear trend is that it suggests that vowel information is distributed fairly uniformly across the syllable, rather than being concentrated either in the formant transition portions or in the quasisteady-state portion. (Typically, $60 \%$ deletion resulted in the removal of most, but not all, of the quasi-steady-state portion of a short-vowel syllable, whereas $90 \%$ deletion 


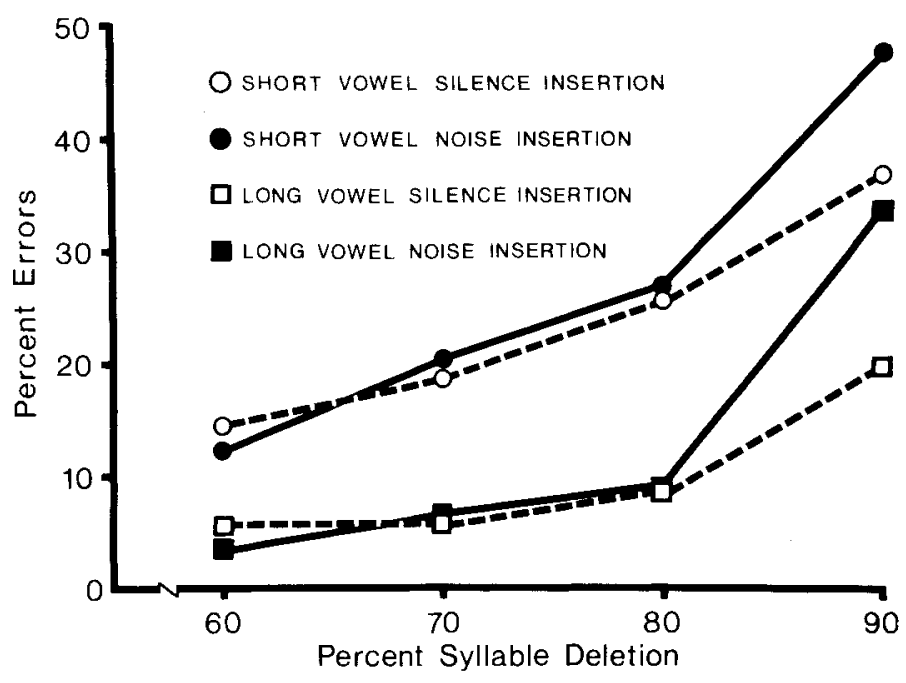

Figure 1. Error rates for each of the modified syllable conditions.

removed all of the quasi-steady-state portion plus more than half of each transition portion).

What, then, is the approximate minimal amount of spectral information needed to cue vowel identity? At this point we can say only that, with $90 \%$ syllable deletion, the minimal value has yet to be reached. In the absence of durational cues, and with $90 \%$ of the syllable replaced by silence, even the spectrally similar short-vowel stimuli were identified correctly $63 \%$ of the time (with chance performance being $33 \%$ ). ${ }^{2}$ Furthermore, of the identification errors made in this condition, $81 \%$ represented confusions with the spectrally more similar vowel category.

As we indicated earlier, both the assimilation and coproduction accounts of coarticulation suggest that vowel information is present throughout a CVC syllable, from release to final closure. Our results, particularly those for the $90 \%$ silence-insertion condition, provide striking support for this claim. One or two pitch periods at both ends of a syllable are sufficient to yield perceptually significant coarticulatory information for vowel identity. In the remainder of this paper, we focus on some particular aspects of the coarticulatory information that might explain the subjects' high level of identification performance.

\section{Acoustical Measurements and \\ Discriminant Analyses}

A formant-tracking algorithm (Interactive Laboratory System) based on linear prediction coding (15 predictor coefficients) was used to measure the center frequencies of the first three formants (F1, F2, and F3) of the shortvowel stimuli. Because we were primarily interested in the information available in the most extreme deletion condition, only the stimuli in the $90 \%$-silence condition were analyzed. ${ }^{3}$ Measurements were taken at the initial syllable release (T1), ${ }^{4}$ at the end of the initial undeleted segment (T2), at the beginning of the final undeleted segment (T3), and at the moment of final closure (T4). Figures $2,3,4$, and 5 display plots of $F 1$ and $F 2$ for the stimuli at each of these temporal locations.
What is most obvious about these figures is the considerable overlap of formant values among the three vowel categories. Each plot shows two principal stimulus clusters distinguished primarily by $F 2$. However, these clusters correspond to the two gender groups rather than to vowel categories. Adding the F3 dimension does not appear to alter substantially the pattern of vowel category overlap.

In order to assess more accurately the statistical separation of the three vowel categories, we carried out a series of discriminant analyses (see Assmann, Nearey, \& Hogan, 1982, for a related treatment of vowel stimuli). In a discriminant analysis (Tasuoka, 1970), selected input variables (e.g., F1, F2, and F3) are weighted and linearly combined into one or more discriminant functions, which define a set of spatial axes. The first discriminant func-

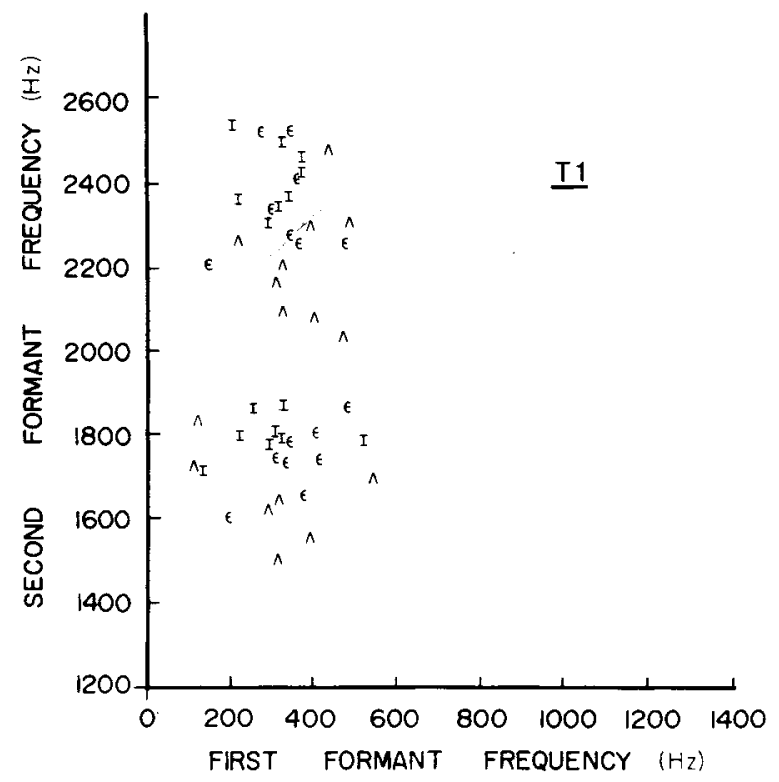

Figure 2. First and second formant frequencies for the short-vowel stimuli at $\mathrm{T} 1$ (initial syllable release). 


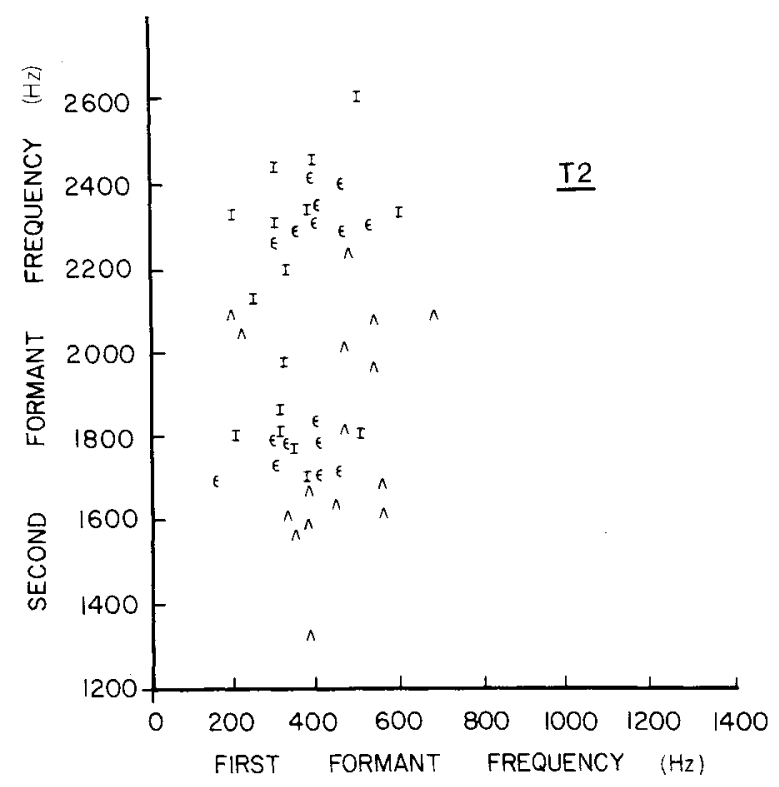

Figure 3. First and second formant frequencies for the short-vowel stimuli at T2 (end of the initial undeleted segment in the $90 \%$ deletion condition).

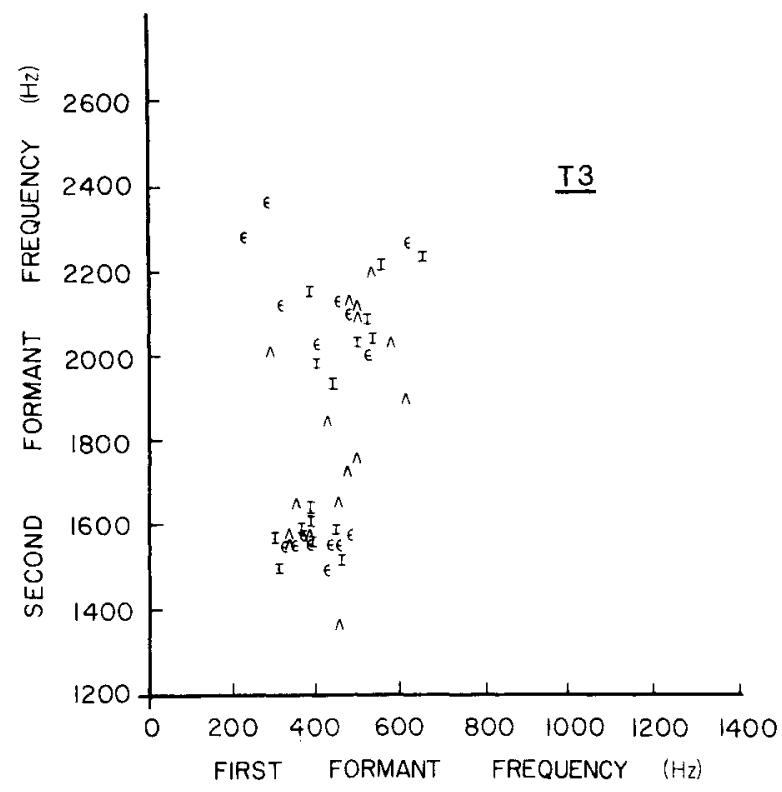

Figure 4. First and second formant frequencies for the short-vowel stimuli at T3 (beginning of the final undeleted segment in the $90 \%$ deletion condition).

tion is chosen so as to yield the maximum possible statistical separation among the groups in question (the categories $/ \mathrm{I} /, / \mathrm{c} /$, and $/ \mathrm{N}$, in the present case), and each subsequent function is similarly selected, from among those that are uncorrelated with previous functions, to maximize group separation. For the cases considered here, the number of discriminant functions is equal to one less than the num- ber of groups (i.e., two). Each discriminant function is tested for statistical significance, and, for any function found to be significant, the weighting coefficients serve to identify those variables that contribute most to group differentiation along that function.

Discriminant scores are determined for all cases (i.e., stimulus items) on each of the derived functions, and "group centroids" are calculated. (The centroids are the mean discriminant scores for each group on the first two discriminate functions.) The discriminant analysis program then enters a "classification" phase: for each item, the probability of its membership in each group is computed given the item's distance from each of the group centroids. The program assigns each item to the category for which the probability of membership is the highest, and a percentage of correct classifications is obtained.

We performed a total of 30 discriminant analyses, each involving different subsets of input variables. In 20 of these analyses, the variables consisted of actual formant frequency measurements at one or more temporal locations. The results of this set of analyses are presented in Table 1 . In the remaining 10 analyses, the variables were formant frequency differences across temporal locations. The results of these analyses are shown in Table 2.

The first column in these tables represents the particular subset of input variables that was assessed in each analysis. The second column shows the number of statistically significant discriminant functions (out of a maximum of two). The third column shows the percentage of correct classifications (i.e., correct assignments of stimulus items to vowel categories), and the fourth displays the correlation (Spearman's $r$ ) between the classification performance of the discriminant analysis program and that

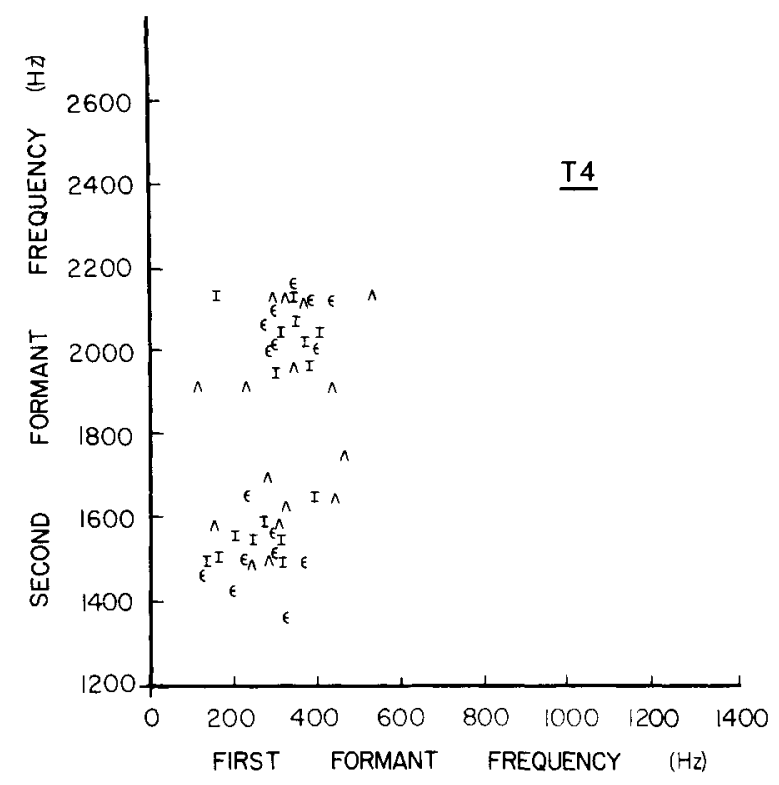

5. First and second formant frequencies for the short-vowel stimuli at $\mathrm{T} 4$ (moment of final closure). 
Table 1

Discriminant Analyses of Actual Formant Frequencies

\begin{tabular}{lccc}
\hline \multicolumn{1}{c}{ Input Variables } & $\begin{array}{c}\text { Number of Significant } \\
\text { Discriminant Functions }\end{array}$ & $\begin{array}{c}\text { Percent Correct } \\
\text { Classifications* }\end{array}$ & $\begin{array}{c}\text { Performance Correlation between } \\
\text { Subjects and Discriminant Program** }\end{array}$ \\
\hline F1,F2 at T1 & 0 & 39.58 & $.118, \mathrm{p}=.130$ \\
F1,F2 at T2 & 1 & 56.25 & $.259, \mathrm{p}=.038$ \\
F1,F2 at T3 & 0 & 37.50 & $-.030, \mathrm{p}=.421$ \\
F1,F2 at T4 & 0 & 34.42 & $-.101, \mathrm{p}=.167$ \\
F1,F3 at T1 & 0 & 39.50 & $.097, \mathrm{p}=.177$ \\
F1,F3 at T2 & 0 & 56.25 & $.121, \mathrm{p}=.123$ \\
F1,F3 at T3 & 0 & 39.58 & $-.015, \mathrm{p}=.444$ \\
F1,F3 at T4 & 0 & 35.42 & $.101, \mathrm{p}=.167$ \\
F1,F2,F3 at T1 & 0 & 45.83 & $.209, \mathrm{p}=.078$ \\
F1,F2,F3 at T2 & 1 & 56.25 & $.250, \mathrm{p}=.044$ \\
F1,F2,F3 at T3 & 0 & 41.67 & $.016, \mathrm{p}=.457$ \\
F1,F2,F3 at T4 & 0 & 47.92 & $.095, \mathrm{p}=.181$ \\
F1,F2 at T1 \& T2 & 1 & 62.50 & $.207, \mathrm{p}=.080$ \\
F1,F2,F3 at T2 \& T3 & 1 & 62.50 & $.205, \mathrm{p}=.081$ \\
F1,F2,F3 at T1 \& T4 & 1 & 56.25 & $.062, \mathrm{p}=.278$ \\
F1,F2,F3 at T1 \& T2 & 1 & $.146, \mathrm{p}=.082$ \\
F1,F2,F3 at T3 \& T4 & 54.17 & $-.093, \mathrm{p}=.186$ \\
F1 at T1,T2,T3, \& T4 & 0 & 45.83 & $-.036, \mathrm{p}=.405$ \\
F2 at T1,T2,T3, \& T4 & 0 & 50.00 & $.134, \mathrm{p}=.183$ \\
F3 at T1,T2,T3, \& T4 & 1 & 64.58 & $.113, \mathrm{p}=.222$ \\
\hline
\end{tabular}

*Correct classification rates above $47.9 \%$ represent significant departures from chance $(p<.05) . \quad$ **Spearman's $r$.

Table 2

Discriminant Analyses of Formant Frequency Differences Over Time

\begin{tabular}{|c|c|c|c|}
\hline Input Variables & $\begin{array}{l}\text { Number of Significant } \\
\text { Discriminant Functions }\end{array}$ & $\begin{array}{l}\text { Percent Correct } \\
\text { Classifications* }\end{array}$ & $\begin{array}{c}\text { Performance Correlation between } \\
\text { Subjects and Discriminant Program** }\end{array}$ \\
\hline $\begin{array}{l}\text { F1 (T1-T2,T2-T3,T3-T4)*** } \\
\text { F2 (T1-T2,T2-T3,T3-T4) } \\
\text { F3 (T1-T2,T2-T3,T3-T4) }\end{array}$ & $\begin{array}{l}0 \\
1 \\
0\end{array}$ & $\begin{array}{l}52.08 \\
64.58 \\
47.92\end{array}$ & $\begin{array}{l}.101, p=.249 \\
.142, p=.168 \\
.019, p=.451\end{array}$ \\
\hline F,F2 (T1-T2,T2-T3,T3-T4) & 1 & 77.08 & $.162, p=.137$ \\
\hline $\begin{array}{l}\text { F1,F2 (T1-T2) } \\
\text { F1,F2 (T2-T3) } \\
\text { F1,F2 (T3-T4) }\end{array}$ & $\begin{array}{l}0 \\
1 \\
0\end{array}$ & $\begin{array}{l}41.67 \\
62.50 \\
47.92\end{array}$ & $\begin{array}{r}-.033, p=.413 \\
.274, p=.030 \\
-.099, p=.252\end{array}$ \\
\hline $\begin{array}{l}\text { F1,F2,F3 (T1-T2) } \\
\text { F1,F2,F3 (T2-T3) } \\
\text { F1,F2,F3 (T3-T4) }\end{array}$ & $\begin{array}{l}0 \\
1 \\
0\end{array}$ & $\begin{array}{l}50.00 \\
62.50 \\
47.92\end{array}$ & $\begin{array}{r}-.112, p=.225 \\
.269, p=.033 \\
-.152, p=.151\end{array}$ \\
\hline
\end{tabular}

of our subjects, together with the corresponding alpha level.

All of the analyses listed in Table 1 that include F1 and $\mathrm{F} 2$ at $\mathrm{T} 2$ as input variables yielded a significant discriminant function as well as a correct classification rate that significantly exceeded chance. Only two other sets of variables produced significant discriminant functions: $F 1, F 2$, and $F 3$ at $T 1$ and $T 4$, and $F 2$ alone at $T 1, T 2$, $\mathrm{T} 3$, and T4. This pattern of results confirms the important role traditionally assigned to $F 1$ and $F 2$ in vowel description and, moreover, supports earlier evidence that, in the case of lax vowels, formant frequencies more closely approximate "target" values in the initial portion of a syllable than in the final portion (Stevens, House, \& Paul, 1966). To the extent that vowel formants deviate from target frequency values (i.e., values associated with sustained vowels or vowels produced in isolation), there is typically a marked reduction in the acoustic separation of different vowel categories (Broad, 1976; Stevens \& House, 1963).

In general, the formant frequency measurements taken closest to the midportion of the syllable (i.e., at T2 and T3) yielded the highest rates of correct classification by the discriminant program $(62.5 \%$ when either the first two or the first three formants were used). This level of performance closely matches that of our subjects for those stimuli (63.4\%). Moreover, for the analyses involving F1 and $\mathrm{F} 2$ at $\mathrm{T} 2$ and $\mathrm{T} 3$, there were gross similarities between the program and the subjects in the pattern of errors. In both cases, $/ \mathrm{I} /$ stimuli tended to be misclassified as $/ \varepsilon /$ rather than $/ \Lambda /$, whereas $/ \varepsilon /$ was usually misclassified as $/ \mathrm{I} /$ rather than $/ \mathrm{A} /$ (see Appendices $\mathrm{A}$ and $\mathrm{B}$ ). 
Despite these similarities, however, the correlations between the program and the subjects in correct classification performance were rather small and only two of them (F1 and $F 2$ at $T 2 ; F 1, F 2$, and $F 3$ at $T 2$ ) reached statistical significance $(\mathrm{p}<.05)$.

The discriminant analyses involving formant frequency differences (Table 2) produced a pattern of results generally consistent with those listed in Table 1 . Significant discriminant functions (as well as above-chance levels of classification performance) were obtained for the analyses that included, among the input variables, differences in F1 and $\mathrm{F} 2$ between the temporal locations $\mathrm{T} 2$ and $\mathrm{T} 3$. In addition, the analysis that included only the F2 differences between $\mathrm{T} 1$ and $\mathrm{T} 2, \mathrm{~T} 2$ and $\mathrm{T} 3$, and $\mathrm{T} 3$ and $\mathrm{T} 4$ produced a significant discriminant function. Not surprisingly, the largest rate of correct classification was found for the analysis involving differences across all four measurement lo- cations for both F1 and F2. Here the discriminant program actually exceeded the performance of our subjects. As in the first set of analyses, the correiations between the classification performance of the program and the subjects were small. Only the analyses whose input variables consisted entirely of formant frequency differences between $\mathrm{T} 2$ and $\mathrm{T} 3$ yielded correlations that were significant $(\mathrm{p}<.05)$.

Table 3 shows the standardized canonical coefficients for each significant discriminant function obtained, together with the alpha level for that function. Recall that the absolute value of each coefficient reflects the contribution of the corresponding input variable to the separation of the stimulus groups. Across these various analyses, two general patterns emerge. First, the contribution of F2 is substantially greater than that of either F1 or F3. Second, absolute formant measurements or formant differ-

Table 3

Standardized Canonical Discriminant Function Coefficients for Significant Functions

\begin{tabular}{|c|c|}
\hline $\begin{array}{l}\text { Discriminant Analyses on } \\
\text { Actual Formant Frequencies }\end{array}$ & $\begin{array}{c}\text { Discriminant Analyses on } \\
\text { Formant Frequency Differences }\end{array}$ \\
\hline $\mathrm{F} 1, \mathrm{~F} 2$ at $\mathrm{T} 2(\mathrm{p}=.006)$ & F2(T1-T2.T2-T3,T3-T4) $(p=.0000)$ \\
\hline $\begin{array}{l}\text { F1: }-.7685 \\
\text { F2: } \quad .8655\end{array}$ & $\begin{array}{l}\text { F2(T1-T2): } .0805 \\
\text { F2(T2-T3): } 1.0875\end{array}$ \\
\hline $\mathrm{F} 1, \mathrm{~F} 2, \mathrm{~F} 3$ at $\mathrm{T} 2(\mathrm{p}=.009)$ & F2(T3-T4): .5978 \\
\hline F1: $\quad .6774$ & $\mathrm{~F} 1, \mathrm{~F} 2(\mathrm{~T} 1-\mathrm{T} 2, \mathrm{~T} 2-\mathrm{T} 3, \mathrm{~T} 3-\mathrm{T} 4)(\mathrm{p}=.0004)$ \\
\hline $\begin{array}{l}\text { F2: }-1.3280 \\
\text { F3: } \quad .6914\end{array}$ & $\begin{array}{lr}\text { F1(T1-T2): } & -.0976 \\
\text { F2(T1-T2): } & .0063\end{array}$ \\
\hline $\mathrm{F} 1, \mathrm{~F} 2$ at $\mathrm{T} 2 \& \mathrm{~T} 3(\mathrm{p}=.002)$ & F1(T2-T3): $\quad-.4538$ \\
\hline $\begin{array}{lr}\text { F1(T2): } & .4584 \\
\text { F2(T2): } & -1.9877 \\
\text { F1(T3): } & -.0193\end{array}$ & $\begin{array}{rc}\text { F2(T2-T3): } & 1.0685 \\
\text { F1(T3-T4): } & -.2706 \\
\text { F2(T3-T4): } & .6164 \\
\text { F1 F2(T2-T3) }(\mathrm{p}=0000 \text { ) }\end{array}$ \\
\hline $\begin{array}{c}\mathrm{F} 2(\mathrm{~T} 3): \\
\mathrm{F} 1, \mathrm{~F} 2, \mathrm{~F} 3 \text { at } \mathrm{T} 2 \& \mathrm{~T} 3(\mathrm{p}=.0035)\end{array}$ & $\begin{array}{rc}\mathrm{F} 1, \mathrm{~F} 2(\mathrm{~T} 2-\mathrm{T} 3) & (\mathrm{p}=.0000) \\
\text { F1(T2-T3): } & -.3762 \\
\text { F2(T2-T3): } & 1.0014\end{array}$ \\
\hline $\begin{array}{lr}\text { F1(T2): } & -.4429 \\
\text { F2(T2): } & 2.0425\end{array}$ & $\mathrm{~F} 1, \mathrm{~F} 2, \mathrm{~F} 3(\mathrm{~T} 2-\mathrm{T} 3)(\mathrm{p}=.0001)$ \\
\hline $\begin{array}{l}\text { F3(T2): }-.8097 \\
\text { F1(T3): } \quad .0191 \\
\text { F2(T3): }-1.4639 \\
\text { F3(T3): }-.1634\end{array}$ & $\begin{array}{lr}\text { F1(T2-T3): } & -.3920 \\
\text { F2(T2-T3): } & 1.0274 \\
\text { F3(T2-T3): } & -.0978\end{array}$ \\
\hline \multicolumn{2}{|l|}{$\mathrm{F} 1, \mathrm{~F} 2, \mathrm{~F} 3$ at $\mathrm{T} 1 \& \mathrm{~T} 4(\mathrm{p}=.0434)$} \\
\hline $\begin{array}{lr}\text { F1(T1): } & .4840 \\
\text { F2(T1): } & -2.1092 \\
\text { F3(T1): } & -.4003 \\
\text { F1(T4): } & -.0831 \\
\text { F2(T4): } & 2.8869 \\
\text { F3(T4): } & -.6195\end{array}$ & \\
\hline \multicolumn{2}{|l|}{$\mathrm{F} 1, \mathrm{~F} 2, \mathrm{~F} 3$ at $\mathrm{T} 1 \& \mathrm{~T} 2(\mathrm{p}=.0366)$} \\
\hline $\begin{array}{lr}\text { F1(T1): } & .0365 \\
\text { F2(T1): } & 1.3688 \\
\text { F3(T1): } & -.0258 \\
\text { F1(T2): } & .6403 \\
\text { F2(T2): } & -2.2735 \\
\text { F3(T2): } & .4345\end{array}$ & \\
\hline \multicolumn{2}{|l|}{$\mathrm{F} 2$ at $\mathrm{T} 1, \mathrm{~T} 2, \mathrm{~T} 3, \& \mathrm{~T} 4(\mathrm{p}=.0001)$} \\
\hline $\begin{array}{lr}\text { F2(T1): } & .1969 \\
\text { F2(T2): } & 2.1299 \\
\text { F2(T3): } & -.4296 \\
\text { F2(T4): } & -1.7047 \\
\end{array}$ & \\
\hline
\end{tabular}


ences involving $\mathrm{T} 2$ typically have more weight than those involving the other temporal locations. As we noted earlier, this latter finding suggests that formants more closely approximate their target frequency values at $\mathrm{T} 2$ than at the other locations.

\section{SUMMARY AND CONCLUSIONS}

Listeners identified two sets of /dVd/ syllables under various deletion conditions. As the deletion interval was increased from $60 \%$ to $90 \%$ of overall syllable duration, identification performance declined in a manner suggesting that vowel information is fairly uniformly distributed across the entire syllable. Except for the $90 \%$ deletion condition, in which noise insertion undoubtedly produced substantial forward and backward masking effects, the insertion of silence and broadband noise produced very similar effects on vowel identification. Both forms of syllable modification apparently removed vowel information without creating spurious cues for oral occlusion or frication that might mislead listeners about vowel identity. In all conditions, vowel identification accuracy was surprisingly high. Even in the $90 \%$ silence-insertion condition, with durational cues neutralized, the spectrally similar short-vowel stimuli, /dId/, /ded/, and $/ \mathrm{d} \Lambda \mathrm{d} /$, were identified correctly $63 \%$ of the time, and most of the errors represented confusions with the spectrally more similar vowel category.

The level of subjects' identification performance in the $90 \%$ deletion condition is generally compatible with the results of our discriminant analyses. Several different subsets of input variables (including formant frequencies at particular temporal locations and formant frequency differences over time) were sufficient to yield significant separation of the three vowel categories and above-chance discriminant classification performance. (The most distinctive cue was $\mathrm{F} 2$ and the most informative temporal location was $\mathrm{T} 2$, the end of the initial undeleted segment.) Thus, despite the considerable acoustic overlap among the vowel categories in the $90 \%$ deletion condition (see Figures 2-5), there clearly remained coarticulatory information by which listeners could potentially distinguish the categories.

It is also clear, however, that none of the individual discriminant analyses provided an appropriate model of the decision strategy used by our listeners. The correlations between the performance of the discriminant program and the subjects were simply too small. There are, of course, a number of possible reasons for this discrepancy. We have no reason to suppose that the subjects limited themselves to any of the particular subsets of variables used in the disc-iminant analyses. Although durational information was neutralized, differences in amplitude envelope and/or spectral shape may have provided vowel cues in addition to the formant frequencies and frequency differences that formed the basis of our analyses. Also, listeners may well have used fundamental frequency cues to divide the stimulus set into two gender categories before making the actual vowel category assignments. This would have effectively reduced much of the vowel category overlap. Finally, the weighting coefficients assigned by the discriminant program to the input variables are not likely to be equivalent to those used by the subjects. For the program, these coefficients were optimized with respect to the entire stimulus set before the classification phase began, whereas, for the subjects, no such optimization was possible.

In summary, it is evident that whatever coarticulatory information was used by the subjects in this task, vowel perception is accomplished by a system of remarkably high resolution.

\section{REFERENCES}

AINSWORTH, W. A. (1972). Duration as a cue in the recognition of synthetic vowels. Journal of the Acoustical Society of America, 51, 648-651.

Assmann, P. F., Nearey, T. M., \& Hogan, J. T. (1982). Vowel identification: Orthographic, perceptual, and acoustic aspects. Journal of the Acoustical Society of America, 71, 975-989.

Blumstein, S. E., \& Stevens, K. N. (1980). Perceptual invariance and onset spectra for stop consonants in different vowel environments. Journal of the Acoustical Society of America, 67, 648-662.

BROAD, D. J. (1976). Toward defining acoustic phonetic equivalence for vowels. Phonetica, 33, 401-424.

ELFNER, L. F. (1971). Continuity of alternately sounded tonal signals in a free field. Journal of the Acoustical Society of America, 49, 447-449.

Fowler, C. A. (1980). Coarticulation and theories of extrinsic timing control. Journal of Phonetics, 8, 113-133.

FOWLER, C. A. (1983). Converging sources of evidence on spoken and perceived rhythms of speech. Journal of Experimental Psychology: General, 112, 386-412.

House, A. S. (1961). On vowel duration in English. Journal of the Acoustical Society of America, 33, 1174-1178.

Houtgast, T. (1974). Lateral suppression in hearing. Amsterdam: Academisch Pers B. V.

Jenkins, J. J., Strange, W., \& Edman, T. R. (1983). Identification of vowels in "vowelless" syllables. Perception \& Psychophysics, 34, 441-450.

Kozhevnikov, V. A., \& Chistovich, L. A. (1965). [Speech: Articulation and perception]. Moscow and Leningrad: Nauka. (Translated, Washington: Clearinghouse for Federal Scientific and Technical Information, Joint Publications Research Service, U.S. Department of Commerce, 30, 543.

KUEHN, D., M Moll, K. (1972). Perceptual effects of forward coarticulation. Journal of Speech and Hearing Research, 15, 654-664.

Liberman, A. M., CoOper, F. S., Shankweiler, D. P., \& StuddertKennedy, M. (1967). Perception of the speech code. Psychological Review, 74, 431-461.

LiNDBLom, B. E. F. (1963). Spectrographic study of vowel reduction. Journal of the Acoustical Society of America, 35, 1773-1781.

MermelsteIN, P. (1975, November). Vowel perception in consonantal context. Paper presented at the 90th meeting of the Acoustical Society of America, San Francisco.

OHDE, R. N., \& ShARF, D. J. (1977). Order effect of acoustic segments of VC and CV syllables on stop and vowel identification. Journal of Speech and Hearing Research, 20, 543-554.

OHMAN, S. E. G. (1966). Coarticulation in VCV utterances: Spectrographic measurements. Journal of the Acoustical Society of America, 39, 151-168.

OhMAN, S. E. G. (1967). Numerical model of coarticulation. Journal of the Acoustical Society of America, 41, 310-328.

Perkell, J. (1969). Physiology of speech production: Results and im- 
plications of a quantitative cineradiographic study. Cambridge, MA: M.I.T. Press.

Peterson, G. E., \& Lehiste, I. (1960). Duration of syllable nuclei in English. Joumal of the Acoustical Society of America, 32, 693-703.

Pols, L. C., \& Schouten, M. E. H. (1978). Identification of deleted consonants. Journal of the Acoustical Society of America, 64, 1333-1337,

Stevens, K. N., \& House, A. S. (1963). Perturbations of vowel articulations by consonantal context: An acoustical study. Joumal of Speech and Hearing Research, 6, 111-128.

Stevens, K. N., House, A. S., \& Paul, A. P. (1966). Acoustical description of syllabic nuclei: An interpretation in terms of a dynamic model of articulation. Journal of the Acoustical Society of America, 40, 123-132.

Strange, W., Jenkins, J. J., \& Johnson, T. L. (1983). Dynamic specification of coarticulated vowels. Journal of the Acoustical Society of America, 74, 695-705.

TATSUOKA, M. (1970). Selected topics in advanced statistics: An elementary approach, Numbers 6: Discriminant analysis: The study of group differences. Champaign, IL: Institute for Personality and Ability Testing.

Tekieli, M. E., \& Cullinan, W. L. (1979). The perception of temporally segmented vowels and consonant-vowel syllables. Journal of Speech and Hearing Research, 22, 103-121.

ThURLOW, W. R. (1957). An auditory figure-ground effect. American Journal of Psychology, 74, 653-654.

Thurlow, W. R., \& ElfNer, L. F. (1959). Continuity effects with alternately sounding tones. Journal of the Acoustical Society of America,31, 1337-1339.

VERBRUGGe, R. R., ISENBERG, D. (1978). Syllable timing and vowel perception. Haskins Laboratories Status Report on Speech Research, SR-55/56, 113-122.

WARREN, R. M., \& OBUSEK, C. J. (1971). Speech perception and phonemic restorations. Perception \& Psychophysics, 9, 358-362.

Warren, R. M., Obusek, C. J., \& ACKroff, J. M. (1972). Auditory induction: Perceptual synthesis of absent sounds. Science, 1972, 176, 1149-1151.

Winitz, H., ScheIB, M. E., \& ReEDS, J. A. (1972). Identification of stops and vowels for the burst portion of $/ \mathrm{p}, \mathrm{t}, \mathrm{k} /$ isolated from conversational speech. Journal of the Acoustical Society of America, 51, 1309-1317.

\section{NOTES}

1. Strange et al. included several conditions in their study that were designed to neutralize intrinsic durational information. Apart from the "silent-center" condition in which the initial and final syllable segments were aligned in their original temporal relationships, there was a "shortened silent-center" condition in which the initial and final segments of all syllables were aligned to yield a silent interval matching the shortest one of the original stimuli, and there was also a "lengthened silentcenter" condition in which the longest original silent interval was used. Only the latter condition produced a significantly greater error rate than that for the unmodified syllables. One potential problem with this approach is not only that durational manipulation removes vowel category information, but also that it is likely to create misinformation about vowel identity, so the actual basis of incorrect performance is difficult to ascertain. (See related comments below.)

2. One might argue that the high level of performance in the various deletion conditions reflected the subjects' previous exposure (in roughly $50 \%$ of the cases) to the full (i.e., unmodified) stimuli. Perhaps the subjects learned some of the particular onset or offset properties of the full stimuli and then used this knowledge to identify the partially deleted items. Although this possibility is difficult to rule out completely, an examination of the pattern of errors does not lend it much support. For example, in the short-vowel conditions, there were five cases in which the full stimulus was presented before any of its modified versions and five cases in which the full stimulus was presented after all of its modified versions. The number of errors for the modified items was actually slightly greater in the former cases (156 vs. 153).

3. Preliminary estimates of formant frequencies were obtained from spectrographic measurements. These were used as a check on the accuracy of the formant-tracking algorithm. Within the expected margin of error, the two measures yielded very similar results. The preliminary measurements revealed that, in the $60 \%$ deletion condition, there was virtually no overlap among the three vowel categories in F1 $\times$ F2 $\times \mathrm{F} 3$ space (for formant values immediately adjacent to the deletion intervals). One of our reasons for focusing on the $90 \%$ deletion condition is that discriminant analysis (see below) is uniquely informative only when there is considerable category overlap and considerable uncertainty as to the dimensions that yield greatest group separation.

4. In cases in which the onset of the first formant was delayed relative to the release, the onset value of F1 was assigned to $\mathrm{T} 1$.

Appendix A

Discriminant Classification Results for 30 Analyses Performed

\begin{tabular}{ccccc}
\multicolumn{4}{c}{ F1 at T1,T2,T3,\&T4 } \\
\hline & & \multicolumn{4}{c}{ Classified as } \\
& & $\varepsilon$ & I & $\Lambda$ \\
Actual & $\varepsilon$ & .375 & .250 & .375 \\
Group & $\mathrm{I}$ & .188 & .625 & .188 \\
& $\Lambda$ & .313 & .188 & .500 \\
& & \multicolumn{4}{c}{ \%correct-50.00 }
\end{tabular}

\begin{tabular}{ccccc}
\multicolumn{4}{c}{ F1 at (T1-T2),(T2-T3)\&(T3-T4) } \\
\hline & & \multicolumn{4}{c}{ Classified as } \\
& & $\varepsilon$ & I & A \\
Actual & $\varepsilon$ & .500 & .313 & .188 \\
Group & $\mathrm{I}$ & .250 & .563 & .188 \\
& $\Lambda$ & .313 & .188 & .500 \\
& & \multicolumn{4}{c}{$\%$ correct-52.08 }
\end{tabular}

F2 at $\mathrm{T} 1, \mathrm{~T} 2, \mathrm{~T} 3 \& \mathrm{~T} 4$

\begin{tabular}{lcccc} 
& & \multicolumn{4}{c}{ Classified as } \\
& & $\varepsilon$ & $\mathrm{I}$ & $\wedge$ \\
Actual & $\varepsilon$ & .563 & .375 & .063 \\
Group & $\mathrm{I}$ & .375 & .625 & .000 \\
& $\Lambda$ & .125 & .125 & .750 \\
& & \multicolumn{4}{c}{ \%correct-64.58 }
\end{tabular}

F2 at (T1-T2),(T2-T3)\&(T3-T4)

\begin{tabular}{lcccc} 
& & \multicolumn{4}{c}{ Classified as } \\
& & $\varepsilon$ & $\mathrm{I}$ & $\Lambda$ \\
Actual & $\varepsilon$ & .500 & .375 & .125 \\
Group & $\mathrm{I}$ & .375 & .625 & .000 \\
& $\wedge$ & .125 & .063 & .813 \\
& $\wedge$ & \multicolumn{4}{c}{ \%correct-64.58 }
\end{tabular}

$\mathrm{F} 3$ at $\mathrm{T} 1, \mathrm{~T} 2, \mathrm{~T} 3, \& \mathrm{~T} 4$

\begin{tabular}{lcccc}
\hline & & \multicolumn{4}{c}{ Classified as } \\
Actual & $\varepsilon$ & $\varepsilon$ & $\mathrm{I}$ & $\wedge$ \\
Group & $\mathrm{I}$ & .500 & .250 & .250 \\
& $\Lambda$ & .188 & .563 & .250 \\
& $\wedge$ & .250 & .188 & .563 \\
& & & \% correct- 54.17
\end{tabular}

\begin{tabular}{|c|c|c|c|c|}
\hline \multicolumn{5}{|c|}{ F3 at (T1-T2),(T2-T3)\&(T3-T4) } \\
\hline & & \multicolumn{3}{|c|}{ Classified as } \\
\hline & & $\varepsilon$ & I & $\mathbf{\Lambda}$ \\
\hline Actual & $\varepsilon$ & .438 & .250 & .313 \\
\hline \multirow{2}{*}{ Group } & I & .250 & .438 & .313 \\
\hline & $\Lambda$ & .250 & .188 & .563 \\
\hline
\end{tabular}


$\mathrm{F} 1, \mathrm{~F} 2$ at $\mathrm{T} 1$

\begin{tabular}{|c|c|c|c|c|}
\hline & & \multicolumn{3}{|c|}{ Classified as } \\
\hline & & $\varepsilon$ & I & $\Lambda$ \\
\hline Actual & $\varepsilon$ & .125 & .375 & .500 \\
\hline \multirow[t]{3}{*}{ Group } & I & .000 & .688 & .313 \\
\hline & $\Lambda$ & .313 & .313 & .375 \\
\hline & & \multicolumn{3}{|c|}{$\%$ correct-39.58 } \\
\hline
\end{tabular}

$\mathrm{F} 1, \mathrm{~F} 2$ at $\mathrm{T} 3$

\begin{tabular}{|c|c|c|c|c|}
\hline \multirow{7}{*}{$\begin{array}{l}\text { Actual } \\
\text { Group }\end{array}$} & \multirow{6}{*}{$\begin{array}{l}\boldsymbol{\varepsilon} \\
\mathbf{I} \\
\mathbf{\Lambda}\end{array}$} & \multicolumn{3}{|c|}{ Classified as } \\
\hline & & $\varepsilon$ & I & $\Lambda$ \\
\hline & & .500 & .063 & .438 \\
\hline & & .313 & .188 & .500 \\
\hline & & .313 & .250 & .438 \\
\hline & & \multicolumn{3}{|c|}{$\%$ correct 37.50} \\
\hline & \multicolumn{4}{|c|}{$\mathrm{F} 1, \mathrm{~F} 2$ at $\mathrm{T} 2 \& \mathrm{~T} 3$} \\
\hline & & \multicolumn{3}{|c|}{ Classified as } \\
\hline & & $\varepsilon$ & I & $\Lambda$ \\
\hline Actual & $\varepsilon$ & .438 & .438 & .125 \\
\hline \multirow[t]{3}{*}{ Group } & I & .250 & .688 & .063 \\
\hline & $\Lambda$ & .125 & .125 & .750 \\
\hline & & \multicolumn{3}{|c|}{$\%$ correct- 62.50} \\
\hline
\end{tabular}

$\mathrm{F} 1, \mathrm{~F} 2$ at (T1-T2)

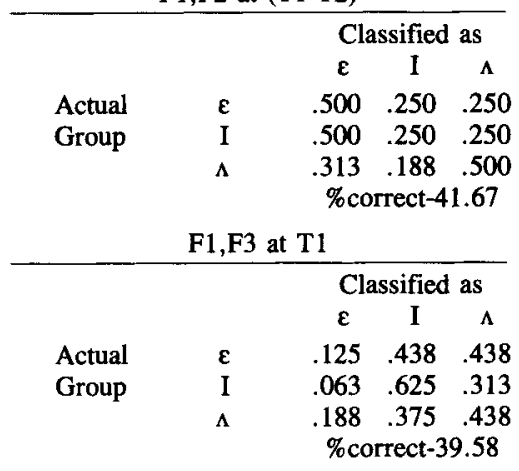

$\mathrm{F} 1, \mathrm{~F} 2$ at $\mathrm{T} 3$

\begin{tabular}{lcccc}
\hline & & \multicolumn{3}{c}{ Classified as } \\
& & $\varepsilon$ & $\mathrm{I}$ & $\Lambda$ \\
Actual & $\varepsilon$ & .500 & .063 & .438 \\
Group & $\mathrm{I}$ & .438 & .125 & .438 \\
& $\Lambda$ & .313 & .125 & .563 \\
& & \multicolumn{3}{c}{ \%correct-39.58 }
\end{tabular}

F1,F2 at (T1-T2),(T2-T3)\&(T3-T4)

\begin{tabular}{lcccc} 
& & \multicolumn{4}{c}{ Classified as } \\
& & $\varepsilon$ & $\mathrm{I}$ & $\Lambda$ \\
Actual & $\varepsilon$ & .625 & .250 & .125 \\
Group & $\mathrm{I}$ & .188 & .813 & .000 \\
& $\Lambda$ & .063 & .063 & .875 \\
& & \multicolumn{4}{c}{$\%$ correct-77.08 }
\end{tabular}

$\mathrm{F} 1, \mathrm{~F} 2, \mathrm{~F} 3$ at $\mathrm{T} 1$

\begin{tabular}{|c|c|c|c|c|}
\hline \multirow{6}{*}{$\begin{array}{l}\text { Actual } \\
\text { Group }\end{array}$} & \multirow{6}{*}{$\begin{array}{l}\boldsymbol{\varepsilon} \\
\mathbf{I} \\
\Lambda\end{array}$} & \multicolumn{3}{|c|}{ Classified as } \\
\hline & & $\varepsilon$ & I & \multirow{2}{*}{$\begin{array}{c}\Lambda \\
.438\end{array}$} \\
\hline & & .188 & .375 & \\
\hline & & .063 & .625 & .313 \\
\hline & & .125 & .313 & .563 \\
\hline & & \multicolumn{3}{|c|}{$\%$ correct -45.83} \\
\hline \multicolumn{5}{|c|}{$\mathrm{F} 1, \mathrm{~F} 2, \mathrm{~F} 3$ at $\mathrm{T} 3$} \\
\hline & & \multicolumn{3}{|c|}{ Classified as } \\
\hline & & $\varepsilon$ & I & $\Lambda$ \\
\hline Actual & $\varepsilon$ & .500 & .125 & .375 \\
\hline \multirow[t]{3}{*}{ Group } & I & .313 & .375 & .313 \\
\hline & $\Lambda$ & .313 & .313 & .375 \\
\hline & & \multicolumn{3}{|c|}{ \%correct-41.67 } \\
\hline
\end{tabular}

$\mathrm{F} 1, \mathrm{~F} 2$ at $\mathrm{T} 2$

\begin{tabular}{|c|c|c|c|c|}
\hline \multirow{6}{*}{$\begin{array}{l}\text { Actual } \\
\text { Group }\end{array}$} & \multirow{6}{*}{$\begin{array}{c}\varepsilon \\
\mathbf{I} \\
\Lambda\end{array}$} & \multicolumn{3}{|c|}{ Classified as } \\
\hline & & $\varepsilon$ & I & $A$ \\
\hline & & .313 & .438 & .250 \\
\hline & & .250 & .563 & .188 \\
\hline & & .063 & .125 & .813 \\
\hline & & \multicolumn{3}{|c|}{ \%correct-56.25 } \\
\hline \multicolumn{5}{|c|}{$\mathrm{F} 1, \mathrm{~F} 2$ at $\mathrm{T} 4$} \\
\hline & & \multicolumn{3}{|c|}{ Classified as } \\
\hline & & $\varepsilon$ & I & $\Lambda$ \\
\hline Actual & $\varepsilon$ & .313 & .375 & .313 \\
\hline \multirow[t]{3}{*}{ Group } & I & .313 & .250 & .438 \\
\hline & $\Lambda$ & .250 & .250 & .500 \\
\hline & & \multicolumn{3}{|c|}{$\%$ correct-35.42 } \\
\hline
\end{tabular}

$\mathrm{F} 1, \mathrm{~F} 2$ at (T2-T3)

\begin{tabular}{|c|c|c|c|c|}
\hline & & \multicolumn{3}{|c|}{ Classified as } \\
\hline & & $\varepsilon$ & I & $\Lambda$ \\
\hline Actual & $\varepsilon$ & .438 & .375 & .188 \\
\hline \multirow[t]{2}{*}{ Group } & I & .188 & .750 & .063 \\
\hline & $\Lambda$ & .188 & .125 & .688 \\
\hline
\end{tabular}

F1,F2 at (T3-T4)

\begin{tabular}{lcccc} 
& \multicolumn{4}{c}{ Classified as } \\
Actual & $\varepsilon$ & .500 & .250 & .250 \\
Group & $\mathrm{I}$ & .375 & .313 & .313 \\
& $\Lambda$ & .188 & .188 & .625 \\
& \multicolumn{4}{c}{$\%$ correct-47.92 } \\
& $\mathrm{F1}, \mathrm{F3}$ at $\mathrm{T} 2$ \\
\hline & \multicolumn{4}{c}{ Classified as } \\
Actual & $\varepsilon$ & .375 & .313 & .313 \\
Group & $\mathrm{I}$ & .188 & .563 & .250 \\
& $\Lambda$ & .125 & .125 & .750 \\
& & & \%correct-56.25
\end{tabular}

$\mathrm{F} 1, \mathrm{~F} 3$ at $\mathrm{T} 4$

\begin{tabular}{llccc}
\hline & & \multicolumn{3}{c}{ Classified as } \\
& & $\varepsilon$ & $I$ & $\Lambda$ \\
Actual & $\varepsilon$ & .500 & .313 & .188 \\
Group & $\mathrm{I}$ & .438 & .313 & .250 \\
& $\Lambda$ & .375 & .375 & .250 \\
& & \multicolumn{3}{c}{ \%correct-35.42 }
\end{tabular}

F1,F2,F3 at T1\&T4

\begin{tabular}{|c|c|c|c|c|}
\hline & & \multicolumn{3}{|c|}{ Classified as } \\
\hline & & $\varepsilon$ & I & $\boldsymbol{\Lambda}$ \\
\hline Actual & $\varepsilon$ & .313 & .313 & .375 \\
\hline \multirow[t]{2}{*}{ Group } & I & .313 & .625 & .063 \\
\hline & $\Lambda$ & $\begin{array}{c}.188 \\
\% \text { co }\end{array}$ & .063 & $\begin{array}{c}.750 \\
6.25\end{array}$ \\
\hline
\end{tabular}

$\mathrm{F} 1, \mathrm{~F} 2, \mathrm{~F} 3$ at $\mathrm{T} 2$

\begin{tabular}{|c|c|c|c|c|}
\hline \multicolumn{3}{|c|}{ Classified as } & & \\
\hline \multirow{5}{*}{$\begin{array}{l}\text { Actual } \\
\text { Group }\end{array}$} & \multirow{5}{*}{$\begin{array}{l}\varepsilon \\
\mathbf{I} \\
\Lambda\end{array}$} & $\varepsilon$ & & $\Lambda$ \\
\hline & & .313 & .438 & .250 \\
\hline & & .063 & .688 & .250 \\
\hline & & .188 & .125 & .688 \\
\hline & & \multicolumn{3}{|c|}{$\%$ correct-56.25 } \\
\hline \multicolumn{5}{|c|}{$\mathrm{F} 1, \mathrm{~F} 2, \mathrm{~F} 3$ at $\mathrm{T} 4$} \\
\hline & & \multicolumn{3}{|c|}{ Classified as } \\
\hline & & $\varepsilon$ & I & $\wedge$ \\
\hline & $\varepsilon$ & .563 & .250 & .188 \\
\hline \multirow[t]{3}{*}{ Group } & I & .250 & .500 & .250 \\
\hline & $\Lambda$ & .250 & .375 & .375 \\
\hline & & \multicolumn{3}{|c|}{$\%$ correct- 47.92} \\
\hline
\end{tabular}


$\mathrm{F} 1, \mathrm{~F} 2, \mathrm{~F} 3$ at $\mathrm{T} 1 \& \mathrm{~T} 2$

\begin{tabular}{|c|c|c|c|c|}
\hline & & \multicolumn{3}{|c|}{ Classified as } \\
\hline & & $\varepsilon$ & I & $\Lambda$ \\
\hline Actual & $\varepsilon$ & .375 & .438 & .188 \\
\hline \multirow[t]{2}{*}{ Group } & I & .250 & .563 & .188 \\
\hline & $\Lambda$ & .250 & .063 & .688 \\
\hline
\end{tabular}

$\mathrm{F} 1, \mathrm{~F} 2, \mathrm{~F} 3$ at $\mathrm{T} 2 \& \mathrm{~T} 3$

\begin{tabular}{lcccc} 
& & \multicolumn{4}{c}{ Classified as } \\
& & $\varepsilon$ & $I$ & $\Lambda$ \\
Actual & $\varepsilon$ & .438 & .438 & .125 \\
Group & $\mathrm{I}$ & .250 & .688 & .063 \\
& $\Lambda$ & .125 & .125 & .750 \\
& & & \%correct-62.50
\end{tabular}

$\mathrm{F} 1, \mathrm{~F} 2, \mathrm{~F} 3$ at $\mathrm{T} 3 \& \mathrm{~T} 4$

Classified as e I $\Lambda$

$\begin{array}{lllll}\text { Actual } & \varepsilon & .500 & .250 & .250\end{array}$

$\begin{array}{lllll}\text { Group } & \mathrm{I} & .250 & .438 & .313\end{array}$

$\begin{array}{llll}1 & .250 & .438 & .313 \\ \wedge & .313 & .250 & .438\end{array}$

$\%$ correct- 45.83
$\mathrm{F} 1, \mathrm{~F} 2, \mathrm{~F} 3$ at $(\mathrm{T} 1-\mathrm{T} 2)$

\begin{tabular}{lcccc} 
& & \multicolumn{4}{c}{ Classified as } \\
Actual & & $\varepsilon$ & $\mathrm{I}$ & $\Lambda$ \\
Group & $\mathrm{I}$ & .500 & .250 & .250 \\
& $\Lambda$ & .250 & .500 & .250 \\
& & .313 & .188 & .500 \\
& & & \%correct-50.00
\end{tabular}

F2,F2,F3, at (T2-T3)

\begin{tabular}{|c|c|c|c|c|}
\hline \multirow{6}{*}{$\begin{array}{l}\text { Actual } \\
\text { Group }\end{array}$} & \multirow{6}{*}{$\begin{array}{l}\boldsymbol{\varepsilon} \\
\text { I }\end{array}$} & \multicolumn{3}{|c|}{ Classified as } \\
\hline & & $\varepsilon$ & I & \multirow{2}{*}{$\begin{array}{c}\wedge \\
.188\end{array}$} \\
\hline & & .438 & .375 & \\
\hline & & .188 & .750 & .063 \\
\hline & & .188 & .125 & .688 \\
\hline & & \multicolumn{3}{|c|}{$\%$ correct-62.50 } \\
\hline \multicolumn{5}{|c|}{$\mathrm{F} 1, \mathrm{~F} 2, \mathrm{~F} 3$ at $(\mathrm{T} 3-\mathrm{T} 4)$} \\
\hline & & \multicolumn{3}{|c|}{ Classified as } \\
\hline & & $\varepsilon$ & 1 & $\Lambda$ \\
\hline Actual & $\varepsilon$ & .500 & .313 & .188 \\
\hline \multirow[t]{2}{*}{ Group } & I & .250 & .375 & .375 \\
\hline & $A$ & .313 & .125 & .563 \\
\hline
\end{tabular}

Appendix B

Subjects' Classification Results on 90\% Deleted Syllables (Short Vowels)

\begin{tabular}{|c|c|c|c|c|}
\hline \multicolumn{5}{|c|}{ Syllables (Short Vowels) } \\
\hline & \multicolumn{4}{|c|}{ Classified as } \\
\hline \multirow{5}{*}{$\begin{array}{l}\text { Actual } \\
\text { Group }\end{array}$} & & & I & $\Lambda$ \\
\hline & $\varepsilon$ & .600 & .340 & .060 \\
\hline & I & .290 & .670 & .040 \\
\hline & $\Lambda$ & .280 & .080 & .640 \\
\hline & & $\% \mathrm{cc}$ & rect-6 & 3.40 \\
\hline
\end{tabular}

(Manuscript received January 27, 1984;

revision accepted for publication September 17, 1984.) 